\title{
FARMACOCINÉTICA Y FARMACODINAMIA DEL DIÓXIDO DE CLORO
}

\author{
Pharmacokinetics and pharmacodynamics of chlorine dioxide
}

\author{
Alberto Rubio-Casillas \\ Laboratorio Clínico, Hospital Regional de Autlán, Secretaría de Salud Jalisco, México. \\ *Autor para correspondencia: alberto-rubioc@hotmail.com \\ Pablo Campra-Madrid \\ Grupo de Investigación en Modelado Digestivo AGR152, Universidad de Almería, España.
}

\begin{abstract}
Resumen
El dióxido de cloro $\left(\mathrm{ClO}_{2}\right)$ se usa ampliamente como desinfectante de agua potable en muchos países. Por su capacidad antibiótica y antiviral, ha despertado interés como potencial agente terapéutico con respecto a la enfermedad de COVID-19, SIDA e Influenza. Como resultado de este debate en entornos científicos y gubernamentales, se consideró muy oportuno proporcionar una evaluación actualizada de la farmacocinética y farmacodinamia del $\mathrm{ClO}_{2}$. Los principales hallazgos indican que, debido a su alta reactividad química, el $\mathrm{ClO}_{2}$ se reduce rápidamente en las secreciones orales y gástricas, produciendo el ión clorito $\left(\mathrm{ClO}_{2}{ }^{-}\right)$que se convierte en el agente activo responsable de sus acciones sistémicas. $\mathrm{El} \mathrm{ClO}_{2}$ también mostró potencial para actuar como oxidante o antioxidante dependiendo de la concentración. De particular interés terapéutico son los hallazgos de que, a bajas concentraciones, el $\mathrm{ClO}_{2}^{-}$puede proteger a los eritrocitos del estrés oxidante al mismo tiempo que inhibe la producción excesiva de ácido hipocloroso $(\mathrm{HClO})$ mediada por la mieloperoxidasa (MPO), revirtiendo así las respuestas inflamatorias y la activación de macrófagos. Finalmente la taurina-cloramina representa el producto funcional más relevante formado bajo la influencia del $\mathrm{ClO}_{2}{ }^{-}$, dicha molécula activa el factor nuclear eritroide 2 (Nrf2), (este factor de transcripción regula la expresión inducible de numerosos genes para las enzimas desintoxicantes y antioxidantes), aumenta la expresión de la hemo-oxigenasa ( $\mathrm{HO}-1)$, protege a las células de la muerte causada por el peróxido de hidrógeno $\left(\mathrm{H}_{2} \mathrm{O}_{2}\right)$, mejora la expresión y las actividades de las enzimas antioxidantes, como la superóxido dismutasa, catalasa y glutatión peroxidasa, y contribuye a la resolución del proceso inflamatorio.
\end{abstract}

Palabras clave: dióxido de cloro, clorito, hormesis, taurina-cloramina, mieloperoxidasa.

\begin{abstract}
Chlorine dioxide $\left(\mathrm{ClO}_{2}\right)$ is widely used as a drinking water disinfectant in many countries. Due to its antibiotic and antiviral capacity, it has aroused interest as a potential therapeutic agent with respect to the COVID-19 disease, AIDS and Influenza. As a result of this debate in scientific and governmental settings, it was deemed highly timely to provide an up-to-date assessment of the pharmacokinetics and pharmacodynamics of $\mathrm{ClO}_{2}$. The main findings indicate that, due to its high chemical reactivity, $\mathrm{ClO}_{2}$ is rapidly reduced in oral and gastric secretions, producing chlorite $\left(\mathrm{ClO}_{2}{ }^{-}\right)$, which becomes the active agent responsible for its systemic actions. $\mathrm{ClO}_{2}$ also showed potential to act as an oxidant or antioxidant depending on the concentration. Of particular therapeutic interest are the findings that, at low concentrations, $\mathrm{ClO}_{2}^{-}$can protect erythrocytes from oxidative stress while inhibiting excessive production of hypochlorous acid $(\mathrm{HClO})$ mediated by myeloperoxidase (MPO), thus reversing the inflammatory responses and macrophage activation. Finally, taurine-chloramine represents the most relevant functional product formed under the influence of $\mathrm{ClO}_{2}{ }^{-}$, said molecule activates the erythroid nuclear factor 2 (Nrf2), (this transcription factor regulates the inducible expression of numerous genes for detoxifying and antioxidant enzymes), increases the expression of heme-oxygenase ( $\mathrm{HO}-1$ ), protects cells from death caused by hydrogen peroxide $\left(\mathrm{H}_{2} \mathrm{O}_{2}\right)$, improves the expression and activities of antioxidant enzymes, such as superoxide dismutase, catalase and glutathione peroxidase, and contributes to the resolution of the inflammatory process.
\end{abstract}

Key words: chlorine dioxide, chlorite, hormesis, taurine-chloramine, myeloperoxidase. 


\section{Introducción}

$\mathrm{El} \mathrm{ClO} 2$ es un gas de color amarillo que se puede descomponer rápidamente en el aire. Debido a que el $\mathrm{ClO}_{2}$ es muy reactivo, puede inactivar virus, bacterias y otros microorganismos en el agua. Aproximadamente el $5 \%$ de las grandes instalaciones de tratamiento de agua (que atienden a más de 100.000 personas) en los Estados Unidos utilizan el $\mathrm{ClO}_{2}$ para tratar el agua potable. Se estima que 12 millones de personas pueden estar expuestas de esta manera al $\mathrm{ClO}_{2}$ y al $\mathrm{ClO}_{2}^{-}$. En las comunidades que usan $\mathrm{ClO}_{2}$ para tratar el agua potable, el $\mathrm{ClO}_{2}$ y su subproducto, el ion $\mathrm{ClO}_{2}^{-}$, pueden estar presentes en niveles bajos en el agua del grifo (US-ASTDR (2004). La EPA (Agencia de Protección Ambiental) ha establecido la concentración máxima en el agua potable a 0,8 miligramos por litro (mg / L) para el $\mathrm{ClO}_{2}$ y 1,0 mg / L para el ion $\mathrm{ClO}_{2}{ }^{-}$.

La FDA (Food and Drug Administration) de los Estados Unidos de América y la COFEPRIS (Comisión Federal para la Protección contra Riesgos Sanitarios) en México afirman que el consumo del $\mathrm{ClO}_{2}$ provoca insuficiencia renal y hepática, además destruye los glóbulos rojos. En el paradigma de la administración de fármacos, determinar la dosis correcta de un fármaco suele ser un desafío. Anteriormente, se ha observado que varios fármacos demuestran efectos contradictorios per se, a concentraciones altas y bajas. Esta dualidad en el efecto de un fármaco a diferentes concentraciones se conoce como hormesis (Bhakta-Guha y Efferth, 2015). Durante varias décadas se creyó que la dosificación del fármaco sigue un patrón lineal, generando un enorme desconocimiento acerca de las respuestas en la zona de concentraciones bajas (Calabrese y Baldwin, 2001). No obstante, en los últimos años, varios estudios han mostrado una respuesta inversa a distintas concentraciones de un fármaco en el mismo individuo, descartando así por completo los modelos de linearidad y respuesta umbral de determinación de concentración (Calabrese et al., 2010). Esta reacción, conocida como "respuesta bifásica a la concentración", ha mostrado importancia para establecer la administración de un fármaco (Calabrese, 2001; Huang y Zheng, 2006; Day y Suzuki, 2006; Calabrese, 2014).

Está bien documentado que el estrés ambiental leve como resultado de dosis bajas de estímulos estresantes a menudo incita a la respuesta adaptativa al estrés en los individuos para mantener la homeostasis (Kuoda e Iki, 2010; Martins et al., 2011). También cumple con el hecho de que, si bien dosis más altas de una sustancia tóxica pueden ser claramente dañinas, pequeñas dosis de la misma pueden promover la salud, gobernada por el crecimiento y el desarrollo (Calabrese, 2001; Schumacher, 2009). Los efectores externos (estímulos), como los factores estresantes o agresores que inducen estrés en concentraciones más altas, a menudo se denominan hormetinas (Menendez et al., 2013; Mattson, 2008). En esta coyuntura, resulta imperativo establecer que el término "estrés" en sí mismo puede tener múltiples implicaciones. En el contexto de esta revisión, nos referimos parámetro, extrínseco o intrínseco, que puede inducir una desviación de los procesos fisiológicos normales del cuerpo (Bhakta-Guha y
Efferth, 2015). La exposición al estrés a menudo provoca vías destinadas a combatir el mismo, que se conocen como respuestas al estrés (Dattilo et al., 2015). Varias de estas respuestas a menudo requieren la estimulación de vías de supervivencia (Rattan, 2006). Las hormetinas pueden ser de origen biológico, físico o químico (Kouda e Iki, 2010; Richardson, 2009). La generación de la respuesta adaptativa a exposiciones leves continuas a tales factores estresantes es un rasgo conservado evolutivamente, que a la larga protege a un individuo contra futuros ataques de alta concentración y estrés (Martins et al., 2011). A este respecto, una revisión exhaustiva (Calabrese y Baldwin, 2003) recopiló una serie de relaciones dosis-respuesta horméticas inducidas por agentes inorgánicos, incluidos agentes tóxicos de gran interés ambiental y de salud pública (por ejemplo, arsénico, cadmio, plomo, mercurio, selenio y zinc).

Por ello, en este artículo revisaremos el estado del conocimiento experimental sobre toxicidad, acción viricida / antiviral, farmacocinética y farmacodinamia del $\mathrm{ClO}_{2} / \mathrm{ClO}_{2}{ }^{-}$ con el objetivo de buscar mecanismos horméticos que puedan inducir respuestas adaptativas al estrés que expliquen sus supuestas propiedades terapéuticas.

\section{Toxicidad}

El perfil toxicológico del $\mathrm{ClO}_{2}$, y de su primer producto reductor, el anión clorito $\left(\mathrm{ClO}_{2}^{-}\right)$, ha sido ampliamente estudiado en ensayos con animales y revisado en sucesivos informes técnicos de la administración estadounidense (USEPA, 2000; US-ASTDR, 2004). En estos estudios, se han informado reacciones tóxicas por encima de diferentes niveles de exposición, después de las vías oral y de inhalación. Las reacciones adversas consistieron en irritación de la vía oral y digestiva, anemia y metahemoglobinemia, función tiroidea alterada, neurotoxicidad con retraso en el desarrollo cerebral en cachorros. Después de una revisión exhaustiva de los estudios en animales, la US-ASTDR (2004) concluyó que la dosis máxima probada entre todos los estudios revisados en los que no se han observado efectos adversos (nivel NOAEL) debe fijarse en $3 \mathrm{mg}\left(\mathrm{ClO}_{2} / \mathrm{ClO}_{2}^{-}\right) /$ $\mathrm{Kg} /$ día. Se concluyó que el nivel más bajo de efectos adversos observado en esta revisión fue de 5,7 mg / kg / día. Estos niveles se obtuvieron después de un estudio final en animales ordenado por la EPA de EE. UU. (Gill et al, 2000) en el que se caracterizó la toxicidad en un estudio de 2 generaciones para examinar los puntos finales reproductivos, del desarrollo, neurológicos y hematológicos en ratas expuestas al clorito de sodio $\left(\mathrm{NaClO}_{2}\right)$ en el agua potable, incluidos los grupos sensibles.

Aunque hasta la fecha se han informado pocos reportes clínicos de toxicidad en humanos, los estudios en animales has mostrado efectos del $\mathrm{ClO}_{2}$ y el $\mathrm{ClO}_{2}^{-}$que son similares a los observados en personas expuestas a cantidades muy altas de estos químicos. En un ensayo en primates no humanos, se estudiaron las crecientes toxicidades sub-crónicas de la administración oral de $\mathrm{ClO}_{2}, \mathrm{NaClO}_{2}, \mathrm{NaClO}_{3}$ y $\mathrm{NH}_{2} \mathrm{Cl}$ en monos verdes africanos durante 30-60 días. Se registró una 
inhibición reversible del metabolismo de la tiroides a dosis sub-crónicas de $9 \mathrm{mg} / \mathrm{kg} /$ día de $\mathrm{ClO}_{2}$, correspondientes a 100 $\mathrm{mg} / \mathrm{L}$ en el agua potable, pero no se observaron efectos a 3 $\mathrm{mg} / \mathrm{kg} /$ día (Bercz et al., 1982). La ingestión de $\mathrm{ClO}^{-}$en primates a dosis elevadas provocó una disminución del recuento de eritrocitos, así como un aumento de las transaminasas. Curiosamente, la mayoría de las dosis de $\mathrm{ClO} 2$ indujeron un estrés oxidativo auto-compensante en la hematopoyesis, ya que ocurrió un fenómeno de rebote en la síntesis de hemoglobina y glóbulos rojos, lo que sugiere un efecto hormético que se discutirá más adelante. Además, no se detectó inhibición de la tiroides después del uso de $\mathrm{ClO}_{2}^{-}$ en concentraciones de hasta $60 \mathrm{mg} / \mathrm{kg} /$ día (Bercz et al., 1982). El efecto tiroideo selectivo de $\mathrm{ClO}_{2}$ fue paradójico ya que el $\mathrm{ClO}_{2}$ se redujo rápidamente por las secreciones orales y gástricas a especies no oxidantes, presumiblemente cloruro $\left(\mathrm{Cl}^{-}\right)$.

En uno de los primeros estudios en humanos ordenados por la US-EPA (Lubbers et al., 1982), se evaluó la tolerancia aguda a una dosis en aumento a partir de la administración oral de diferentes desinfectantes de agua clorada. No se detectó toxicidad sistémica por debajo de la dosis máxima de $24 \mathrm{mg} /$ $\mathrm{L}$ de $\mathrm{ClO}_{2}$ y de $2,4 \mathrm{mg} / \mathrm{L}_{\text {de }} \mathrm{ClO}_{2}^{-}$, ingerida en dos tomas diarias con 4 horas de separación. En otro experimento de toxicidad sub-crónica, la ingestión oral diaria de $\mathrm{ClO}_{2}$ a una concentración de $5 \mathrm{mg} / \mathrm{L}$ durante 12 semanas consecutivas no produjo efectos adversos clínicos indeseables obvios. La ausencia de toxicidad del $\mathrm{ClO}_{2}^{-}$en humanos por debajo de este nivel de NOAEL establecido por la US-ASTDR se ha informado en ensayos clínicos controlados recientes. En un estudio de fase I, controlado con placebo, de seguridad y tolerabilidad en pacientes con Esclerosis Lateral Amiotrófica (ELA), Miller et al., (2014) probaron dosis únicas ascendentes de $0,2,0,8,1,6$ y $3,2 \mathrm{mg} / \mathrm{kg}$ de $\mathrm{NaClO} 2$ endovenoso. Después del tratamiento, los pacientes fueron monitoreados para una variedad de variables de seguridad y estado clínico durante y durante $8 \mathrm{~h}$ después de las infusiones, uno, cuatro y siete días después de la dosificación. Todas las dosis fueron generalmente seguras y bien toleradas y no hubo eventos adversos graves relacionados con el tratamiento. En un estudio adicional de fase II en pacientes con ELA, no se observaron efectos adversos cuando se administraron $2 \mathrm{mg} /$ $\mathrm{kg} / \mathrm{día}$ en exposiciones sub-agudas repetidas mensualmente (3-5 días) (Miller et al, 2015).

En niveles extremos de exposición, se han descrito eventos adversos por intentos de suicidio al ingerir dosis masivas de $\mathrm{ClO}_{2}^{-}$. Después de la intoxicación por una dosis única de $10 \mathrm{gr}$ de $\mathrm{NaClO} 2$, aproximadamente $142 \mathrm{mg}$ / kg (Lin y Lim, 1993), el estrés oxidativo excesivo provocó irritación en el tracto digestivo acompañada de náuseas, vómitos e insuficiencia renal. En otro intento de suicidio de un hombre adulto que ingirió alrededor de $100 \mathrm{ml}$ de solución de $\mathrm{NaClO}_{2}$ al 28\% (Gebhardtova et al., 2014), las pruebas de laboratorio iniciales revelaron $40 \%$ de formación de metahemoglobina e insuficiencia renal aguda.

La toxicidad mínima observable (LOAEL) se esperaría a partir de los $5.7 \mathrm{mg} \mathrm{kg} /$ día, equivalente a $420 \mathrm{mg} /$ día para un humano adulto promedio. En conclusión, no hay evidencia experimental disponible para sostener que administrando dosis inferiores a $3 \mathrm{mg} / \mathrm{kg} /$ día exista un riesgo de toxicidad sistémica o variaciones en los parámetros clínicos relevantes. Esta dosis es equivalente a $210 \mathrm{mg}$ de $\mathrm{ClO}_{2}$ por día para un adulto promedio de $70 \mathrm{~kg}$.

\section{Actividad viricida/antiviral}

Se ha descrito la actividad viricida del $\mathrm{ClO}_{2}$ in vitro frente a diferentes virus humanos y animales (Ogata y Shibata, 2008; Sanekata et al., 2010). Por ejemplo, se informó que el $\mathrm{ClO}_{2}$ fue capaz de inactivar el virus de la influenza humana en un $99,9 \%$ a los 15 segundos usando 1 ppm, contra el virus del sarampión esta inactivación se logró a los 30 segundos usando $10 \mathrm{ppm}$ y contra el virus del herpes se logró a los 15 segundos segundos usando 10 ppm (Sanekata et al., 2010). Otros investigadores demostraron que el $\mathrm{ClO}_{2}$ es capaz de destruir el virus de la Poliomielitis usando 1-2 ppm, el de la Hepatitis A con 7.5 ppm, el Rotavirus con 0.2 ppm, 10 ppm para el virus VIH-1 y 2.1 ppm para el coronavirus que causó el SARS (citado en Miura y Shibata, 2010).

El uso potencial como profiláctico contra infecciones virales se demostró para la influenza A por inhalación en ratones (Ogata y Shibata, 2008). En cuanto al mecanismo de acción viricida directa de $\mathrm{ClO}_{2} / \mathrm{ClO}_{2}{ }^{-}$, se han propuesto mecanismos basados en la oxidación de residuos de aminoácidos clave en la envoltura proteica viral, como la desnaturalización del virus RBD (dominio de unión al receptor), aboliendo así su capacidad de unión al receptor (Ogata, 2007; 2012). Según estudios realizados con marcaje radiactivo, el $\mathrm{ClO}_{2}^{-}$tiene una vida media de 3,5 horas (AbdelRahman et al., 1982), tiempo suficiente para producir efectos antivirales plasmáticos directos, que consistirían en la oxidación de los aminoácidos que se encuentran en la envoltura proteica de los virus. En particular, es importante la oxidación de residuos de tiol (-SH) de tirosina, treonina y triptófano. La formación de puentes disulfuro tanto en la proteína de pico del SARS-CoV-2 como en los receptores ACE2 de las células alveolares humanas se ha propuesto como un activador de un cambio conformacional que promueve la unión del virus (Hati y Bhattacharya, 2020). Al reducir el estrés oxidativo como uno de los mecanismos patogénicos del virus, las dosis terapéuticas de $\mathrm{ClO}_{2} / \mathrm{ClO}_{2}^{-}$ podrían prevenir la formación de enlaces disulfuro y la unión con ACE2 y la proteína de espiga.

Es importante destacar que recientemente se ha informado del primer ensayo in vivo que describe un efecto antiviral del $\mathrm{ClO}_{2}$ contra el coronavirus aviar (ZambranoEstrada et al., en prensa). El tratamiento con $\mathrm{ClO}_{2}$ tuvo un impacto marcado en la infección viral. Es decir, los títulos virales fueron 2,4 veces más bajos y la mortalidad se redujo a la mitad en los embriones infectados que fueron tratados con $\mathrm{ClO}_{2}$. La infección provocó anomalías en el desarrollo independientemente del tratamiento. Se observaron lesiones típicas de las infecciones por ese virus en todos los 
embriones inoculados, pero la gravedad tendió a ser significativamente menor en los embriones tratados con $\mathrm{ClO}_{2}$. No se encontró evidencia macroscópica o microscópica de toxicidad causada por el $\mathrm{ClO}_{2}$ a las dosis utilizadas en este estudio (Zambrano-Estrada et al., en prensa). Además, recientemente se han publicado los resultados del primer estudio clínico que demuestra la eficacia del $\mathrm{ClO}_{2}$ para el tratamiento de la enfermedad por COVID-19. En esta investigación se analizó el efecto del $\mathrm{ClO}_{2}$ en la evolución clínica de 20 pacientes con infección activa por el virus SarsCoV-2. El grupo control consistió de 20 pacientes que no recibieron $\mathrm{ClO}_{2}$. El grupo experimental consistió en 20 pacientes que recibieron una solución oral de $\mathrm{ClO}_{2}$ a una concentración de $30 \mathrm{mg} / \mathrm{L}$ (muy por debajo del NOAEL) durante 21 días. Al comparar el grupo experimental con el grupo control al séptimo día después de la manifestación de los síntomas, se encontró una diferencia significativa en el grupo experimental con respecto al grupo control para los síntomas Fiebre ( $p: 0000)$, Tos ( $p: 0.0000)$, Escalofríos ( $p$ : $0,0000)$ y Disnea ( $p: 0,0006)$. Al realizar la comparación visual análoga del dolor en el grupo control y en el grupo experimental, se encontró que en todos los ítems que componen la escala disminuyó significativamente en este grupo con respecto al grupo control ( $p$ : 0.0000; p:00017). Al día 14, la diferencia fue mayor ( $p: 0,000 ; p: 0,0043$ ). Al evaluar ambos grupos (Control y Experimental) en el laboratorio, se encontró diferencia para los valores de los parámetros proteína $C$ reactiva $(P C R)$ el día 7 ( $p: 0,0001)$ y la LDH (Lactato Deshidrogenasa) $(0,0036)$, con puntuaciones más altas para el grupo experimental; Dímero-D el día 7 ( $p$ : 0,0194) y el día 14 ( $p$ : 0,0029); se encontró diferencia en todos los parámetros. Los resultados en general $(p<0,05)$ confirmaron la hipótesis de que el dióxido de cloro es eficaz en el tratamiento de COVID-19 (Insignares-Carrione et al., 2021).

$\mathrm{El} \mathrm{ClO}_{2}^{-}$también produce efectos antivirales/viricidas. Un estudio realizado en los años 90 tuvo como objetivo determinar los efectos del $\mathrm{ClO}_{2}^{-}$(WF10) sobre la replicación del VIH y sobre la infectividad de las partículas libres del VIH (Raffanti et al., 1998) Se demostró que el complejo WF10 exhibe una actividad antiviral significativa contra el VIH. Estos investigadores demostraron que el complejo $\mathrm{ClO}_{2}^{-}$-oxígeno modifica la glicoproteína gp120 de la envoltura externa del virión, inhibiendo así su unión a la molécula CD4 de las células T CD4+. La inactivación del VIH está mediada por la actividad oxidativa del complejo $\mathrm{ClO}_{2}^{-}$-oxígeno (Raffanti et al., 1998).

Este mecanismo oxidativo es similar al mediado por el $\mathrm{ClO}_{2}$ para el virus de la influenza; una oxidación de un residuo de triptófano (W153) en la hemaglutinina (una proteína de espiga del virus), aboliendo así su capacidad de unión al receptor. En otras palabras, esta modificación oxidativa induce cambios estructurales en el sitio de unión de la hemaglutinina y perturba su interacción con el receptor de la célula hospedera (Ogata, 2012). La proteína espiga del nuevo coronavirus SARS CoV2 contiene 54 residuos de tirosina, 12 triptófano y 40 residuos de cisteína (Tao et al., 2020. En un trabajo reciente, se utilizaron reconstrucciones $3 \mathrm{D}$ realizadas por computadora, uso de datos a través de estudios en criomicroscopía electrónica y trabajos previos basados en software de realidad aumentada (Insignares-Carrione et al, 2020). Dichas simulaciones permitieron determinar las posiciones de los aminoácidos susceptibles de ser oxidados por el $\mathrm{ClO}_{2}$ y que permite inferir su posible mecanismo de acción sobre el virus SARS-CoV-2. Estos investigadores han postulado que el $\mathrm{ClO}_{2}$ podría oxidar a la cisteína Cys480Cys488, que son clave para la unión entre la espiga del SARSCoV-2 con el receptor de la ACE2 (Insignares-Carrione et al., 2020).

\section{Farmacocinética}

Aún existen pocos estudios en humanos que nos permitan caracterizar la farmacocinética del $\mathrm{ClO}_{2}$, es decir, los procesos de digestión, absorción, distribución, metabolismo y excreción a los que está sometido a través de su paso por el organismo (US-ASTDR, 2004). En este trabajo presentamos una hipótesis basada tanto en las propiedades redox de este gas y sus metabolitos, como en estudios realizados en animales y en dos ensayos clínicos controlados publicados en humanos (Miller et al., 2014; 2015). Químicamente, el $\mathrm{ClO}_{2}$ es un radical libre inestable, con un electrón desapareado que lo convierte en un oxidante fuerte, reduciéndose rápidamente a $\mathrm{ClO}_{2}{ }^{-}$en presencia de especies donantes de electrones, como proteínas y aminoácidos, es decir, los procesos de digestión, absorción, distribución, metabolismo y excreción a los que está sometido a través de su paso por el organismo (US-ASTDR, 2004).

\subsection{Degradación en la cavidad oral/gástrica}

Los datos experimentales más relevantes para caracterizar la farmacocinética provienen de estudios en animales. En estudios in vivo en ratones basados en el marcaje radiactivo de $\mathrm{ClO}_{2}$, Abdel-Rahman et al (1979a; 1984), utilizando cloro marcado radioactivamente $\left(\mathrm{Cl}^{36}\right)$, determinaron una rápida absorción gastrointestinal y una amplia distribución en los tejidos, con un pico plasmático después de una hora de ingestión. La tasa de absorción y la vida media se estimaron en 3,77 y 0,18 horas, respectivamente (Abdel-Rahman et al., 1982).

Bercz et al. (1982) estudiaron el procesamiento oral de soluciones de $\mathrm{ClO}_{2}$ y $\mathrm{ClO}_{2}^{-}$en primates no humanos. Se demostró que la saliva es un poderoso reductor de $\mathrm{ClO}_{2}$, con solo un $5-12 \%$ del contenido inicial restante después de 1 minuto de reacción in vitro. Se sabe que la saliva contiene la enzima peroxidasa (Klebanoff y Luebke, 1965) que aceleraría este proceso de reducción. Además, la saliva humana contiene una amplia gama de biomoléculas, muchas de las cuales son reactivas con el $\mathrm{ClO}_{2}$, incluidos los aminoácidos, los últimos incluyendo la cisteína, triptófano y metionina (Silwood et al., 1999). Bercz et al. (1982) también estudiaron la digestión gástrica del $\mathrm{ClO}_{2}$ "in vivo", recuperando solo el $8 \%$ de la capacidad oxidativa inicial del $\mathrm{ClO}_{2}$ ingerido después de 5 minutos de contacto con el contenido gástrico. 
Sin embargo, no estudiaron la variación en la distribución de la capacidad oxidante entre las posibles especies oxidantes, ni realizaron mediciones en plasma o excreción.

\subsection{Metabolismo}

$\mathrm{El} \mathrm{Cl}^{36}$ absorbido se elimina lentamente de la sangre. Después de $72 \mathrm{~h}$, el $80 \%$ del $\mathrm{Cl} 36$ residual encontrado en el plasma estaba en forma de cloruro y el $20 \%$ en forma de $\mathrm{ClO}_{2}{ }^{-}$. Después de 72 horas, el cloro marcado con un isótopo radiactivo se detectó principalmente en plasma, intestino y estómago, así como en varios tejidos como pulmón y riñón (Abdel-Rahman et al., 1979a). Un pequeño porcentaje del cloro radiactivo inicial $(0,4-0,8 \%)$ se detectó en las células sanguíneas, en especies no identificadas en el organismo antes de su excreción, principalmente como cloruro y $\mathrm{ClO}_{2}{ }^{-}$. Se estimó una tasa de excreción urinaria de 72 horas del $30-35 \%$ del $\mathrm{Cl}^{36}$ que no fue fijado por los tejidos o que permaneció en el plasma, con un pico entre 24 y 48 horas, y una vida media de 44 horas. $\mathrm{El} \mathrm{Cl}^{36}$ excretado se encontró principalmente como cloruro $(\mathrm{Cl}-)(87 \%), \mathrm{ClO}_{2}^{-}(1,3 \%)$ y en menor grado como clorato ( $\mathrm{ClO}_{3}-$ ). En este mismo trabajo, el clorito de potasio se redujo mediante plasma in vitro a cloruro en un $100 \%$, y el $\mathrm{ClO}_{2}$ oral se redujo mediante plasma in vivo en un $82,3 \%$ a $\mathrm{ClO}_{2}^{-}$y un $17,6 \%$ a cloruro. Del total eliminado, $72 \%$ fue en orina y $25 \%$ en heces. En la orina, el cloro marcado en $\mathrm{ClO}_{2}$ y $\mathrm{ClO}_{2}^{-}$se excreta principalmente como ion cloruro, $87 \%$ y $84 \%$ respectivamente. No se detectó la formación de trialometanos a las dosis bajas ensayadas (máximo 1,5 mg/ $\mathrm{kg} /$ día. No se detectó excreción por aire. La absorción y eliminación del $\mathrm{ClO}_{2}$ y sus metabolitos fue más rápida que para el hipoclorito, el componente activo de la lejía común.

$\mathrm{El} \mathrm{ClO}_{2}^{-}$también se absorbe rápidamente en el tracto gastrointestinal. Los niveles plasmáticos máximos de cloro radiomarcado se alcanzaron 2 horas después de la administración de una dosis única de $100 \mathrm{mg} / \mathrm{L} \mathrm{de}^{36} \mathrm{ClO}_{2}^{-}$ (aproximadamente $0,13 \mathrm{mg} / \mathrm{kg}$ ) a ratas Sprague-Dawley. Utilizando datos de excreción urinaria de 72 horas, se estimó que se había absorbido el $35 \%$ de la dosis inicial (Abdel Rahman et al., 1984). La constante de velocidad de absorción y la vida media fueron 0,198 / hora y 3,5 horas, respectivamente (Abdel-Rahman et al., 1982). Debido a la extrema reactividad del $\mathrm{ClO}_{2}$, se reduce rápidamente a $\mathrm{ClO}_{2}^{-}$ en la boca y el estómago cuando reacciona con alimentos, sustancias orgánicas, tejidos $u$ otros materiales que pueden servir como donantes de electrones. Aunque es poco probable que el $\mathrm{ClO}_{2}$ permanezca en el entorno del estómago el tiempo suficiente para ser absorbido, el ión $\mathrm{ClO}_{2}^{-}$puede absorberse y entrar en la sangre (Harrington et al., 1986).

Estos trabajos (Abdel-Rahman et al., 1979b, 1982; Bercz et al., 1982) vienen a apoyar nuestra hipótesis de la reducción del $\mathrm{ClO}_{2}{\text { a } \mathrm{ClO}_{2}^{-}}^{-}$y de este a cloruro en la sangre como base del mecanismo de acción, a través de interacciones redox intermedias con proteínas plasmáticas y enzimas celulares. Abdel-Rahman et al. (1979b) encontraron que, en solución acuosa, el clorito de potasio se reducía parcialmente a cloruro (21\%), pero en menor medida se oxidaba a clorato (7\%), hecho a tener en cuenta a la hora de controlar la calidad y estabilidad de las formulaciones a base de $\mathrm{ClO}_{2}{ }^{-}$ como principio activo. Por tanto, dependiendo del entorno redox y del $\mathrm{pH}$, se puede desencadenar una rápida interconversión entre estos metabolitos en soluciones acuosas iniciales de $\mathrm{ClO}_{2}$ puro, intensificadas tras la digestión oral, gástrica e intestinal (Bercz et al., 1982). EI procesamiento final del $\mathrm{ClO}_{2}$ y sus metabolitos consistiría en su excreción por vía urinaria y fecal, principalmente como cloruro, con menores cantidades de $\mathrm{ClO}_{2}^{-}$y clorato, como se muestra en los trabajos antes mencionados de Abdel-Rahman et al., (1979b; 1984).

\section{Farmacodinamia}

Asimismo, existen pocos trabajos que describen la farmacodinamia del $\mathrm{ClO}_{2}$ y $\mathrm{ClO}_{2}^{-}$in vivo, es decir, los efectos bioquímicos y fisiológicos de esta molécula, sus mecanismos de acción y la relación entre la dosificación de la solución del fármaco y su efecto sistémico terapéutico. Teniendo en cuenta los datos farmacocinéticos, se puede plantear la hipótesis de que el $\mathrm{ClO}_{2}$ administrado por vía oral se reduce rápidamente a $\mathrm{ClO}_{2}^{-}$en la cavidad oral a través de la saliva o en el estómago a través de secreciones ácidas (Bercz et al, 1982). En el intestino delgado, el $\mathrm{ClO}_{2}^{-}$ se absorbería a través de las vellosidades que están abundantemente vascularizadas, absorbiéndose principalmente como tal anión, sin descartar cantidades menores de cloruro generadas por reducción parcial. Posteriormente, tanto el $\mathrm{ClO}_{2}^{-}$absorbido por exposición oral como administrado directamente por vía intravenosa reaccionan oxidando los donantes de electrones de la compleja matriz orgánica de plasma y células sanguíneas, en particular proteínas y aminoácidos.

\subsection{Interacciones entre el $\mathrm{ClO}_{2}-\mathrm{y}$ las enzimas hemo de las células de la sangre periférica} Schempp et al. (2001) informaron que el producto de la reducción de $\mathrm{ClO}_{2}^{-}$catalizada por hemoproteínas de macrófagos es una especie de cloro-oxígeno, probablemente ácido hipocloroso $(\mathrm{HClO})$. La característica común del par redox " $\mathrm{H}_{2} \mathrm{O}_{2} /$ hemoglobina" y " $\mathrm{ClO}_{2}-$ hemoglobina" es la oxidación inicial del hemo por transferencia de 2 electrones, dando lugar a un intermedio de hemo oxidado llamado compuesto I. Por lo tanto, ambos oxidantes se reducen, resultando en el anión hidróxido para $\mathrm{H}_{2} \mathrm{O}_{2}$, mientras que el $\mathrm{ClO}_{2}^{-}$se reduce a $\mathrm{HClO}$, es decir, el $\mathrm{ClO}_{2}$ se convertiría por reducción en $\mathrm{ClO}_{2}^{-}, \mathrm{HClO}_{\text {y }}$ finalmente en cloruro (Abdel-Rahman et al., 1979b). Además, el $\mathrm{HClO}$ puede clorar los residuos de aminoácidos de azufre generando cloraminas como la taurina-cloramina (Tau-Cl), que ejercen una acción oxidante más atenuada y estable que el $\mathrm{HClO}$, modulando así la inflamación excesiva (Schempp et al., 2001). 
5.1.1. Interacción del $\mathrm{ClO}_{2}-$ con la hemoglobina La exposición al $\mathrm{ClO}_{2}^{-}$puede causar metahemoglobinemia, sin embargo este efecto se registró sólo con altas concentraciones. Por ejemplo, los primeros informes documentaron que concentraciones de $\mathrm{ClO}_{2}^{-}$de $100 \mathrm{mg} /$ L y más en la rata causaron una disminución en el número de glóbulos rojos y hemoglobina a los 30 y 60 días de exposición (Heffernan et al., 1979). Otro estudio (Moore y Calabrese, 1982) evaluó la toxicidad del $\mathrm{ClO}_{2}^{-}$en 2 cepas de ratones: una con niveles normales (A / J) y otra con niveles bajos (C57L / J) de Glucosa-6-fosfato deshidrogenasa. Las células deficientes en G6PD tienen una capacidad reducida para producir NADPH, por lo que sintetizan muy poco glutatión (el principal mecanismo de defensa de los eritrocitos contra el estrés oxidativo). Los resultados mostraron que cuando se expusieron a un nivel máximo de 100 ppm de $\mathrm{ClO}_{2}^{-}$durante 30 días, hubo un aumento en la fragilidad osmótica, el volumen corpuscular medio y los niveles de G6PD para ambas cepas, sin embargo, no se detectó metahemoglobinemia. En los animales que fueron expuestos a 1.0 y $10 \mathrm{mg} / \mathrm{L}$ no hubo ninguna de las anomalías antes mencionadas. Las dosis administradas de $\mathrm{NaClO}_{2}$ (hasta $100 \mathrm{mg} / \mathrm{L}$ ) en el agua de bebida no causaron ningún daño tóxico a los riñones de los animales a los 60, 90 y 180 días de exposición (Moore y Calabrese, 1982).

A partir de estos datos, está claro que la destrucción de eritrocitos mediada por el $\mathrm{ClO}_{2}^{-}$se observó solo a concentraciones elevadas, lo que revela que los eritrocitos tienen un sistema de protección antioxidante eficaz. Sin embargo, cuando se administra una alta concentración de $\mathrm{ClO}_{2}^{-}$, este sistema ya no es capaz de neutralizar el agente oxidante y se produce la hemólisis. Los glóbulos rojos normales están sujetos a un alto nivel de estrés oxidativo como resultado de la producción continua del anión superóxido que acompaña a la autooxidación de la hemoglobina ( $\mathrm{Hb}$ ). El anión superóxido se dismuta en peróxido de hidrógeno $\left(\mathrm{H}_{2} \mathrm{O}_{2}\right)$, que luego se convierte en el radical hidroxilo mediante la reacción de Fenton en presencia de hierro. Para hacer frente al estrés oxidativo, los glóbulos rojos están equipados con superóxido dismutasa (SOD1), catalasa, glutatión peroxidasa 1 (GPx1) y tres isoformas de peroxiredoxina (Prx I, Prx II y Prx VI). SOD1 convierte el anión superóxido en $\mathrm{H}_{2} \mathrm{O}_{2}$, que luego es eliminado por la catalasa, GPx1 y Prxs (Rhee y Lee, 2017).

Se ha informado de que el $\mathrm{ClO}_{2}$, el $\mathrm{ClO}_{2}^{-}$y el $\mathrm{C}_{3} \mathrm{O}_{3}$ en el agua potable disminuyeron la concentración de glutatión en sangre y cambiaron la morfología de los eritrocitos en ratas después de 2 meses (Abdel-Rahman et al., 1979a). Sin embargo, las ratas se adaptaron gradualmente al estrés por $\mathrm{ClO}_{2}$ aumentando la actividad de la glutatión reductasa y catalasa (Couri y Abdel-Rahman, 1979). Estos hallazgos son consistentes con el conocido papel protector del glutatión contra el daño inducido por oxidantes (Hill et al., 1964).

5.1.2. El ClO2- es un agente protector de los eritrocitos Aunque la mayoría de las investigaciones han informado un efecto hemolítico del $\mathrm{ClO}_{2}^{-}$en altas concentraciones, recientemente se demostró que el $\mathrm{ClO}_{2}^{-}$a bajas concentraciones es capaz de eliminar la metahemoglobina (Pichert y Arnhold, 2015; Flemming et
El transporte de oxígeno en nuestro organismo se realiza mediante la hemoglobina tetramérica en los glóbulos rojos y la mioglobina monomérica en el tejido muscular. En cada subunidad de ambas proteínas se encuentra presente un grupo protoporfirina IX con un ion hierro central que puede presentar diferentes estados de oxidación. En ambas proteínas, solo el hierro del grupo hemo en estado ferroso $(\mathrm{Fe} 2+)$ puede unirse al oxígeno. Por lo tanto, es importante mantenerlos en un estado reducido. En los eritrocitos, esto se logra principalmente mediante la metahemoglobina reductasa, que convierte la metahemoglobina (que contiene hierro férrico $\left(\mathrm{Fe}^{+}\right)$en hemoglobina ferrosa $(\mathrm{Fe} 2+)$. La formación espontánea de metahemoglobina generalmente ocurre a una tasa baja, sin generar un rendimiento de metahemoglobina superior al 1\% (Van Slyke et al., 1946; Siggaard-Andersen et al., 1972).

De los ensayos clínicos realizados con el fármaco WF10 se sabe que el $\mathrm{ClO}_{2}^{-}$interactúa con las hemoproteínas (Schempp et al., 2001; Jakopitsch et al., 2008; Jakopitsch et al., 2014; Pichert y Arnhold, 2015), que son degradadas por el $\mathrm{ClO}_{2}^{-}$con la pérdida de la estructura del hemo (Pichert y Arnhold, 2015). La solución de fármaco inmunomodulador a base de $\mathrm{ClO}_{2}^{-}$(WF10) y la forma más diluida Oxoferin se aplican para amortiguar estados inflamatorios severos $y$ mejorar los procesos de cicatrización de heridas (Raffanti et al., 1998; McGrath et al., 2002; Veerasam et al., 2006; Yingsakmongkol et al., 2011).

Se demostró que el $\mathrm{ClO}_{2}{ }^{-}$contenido en WF10 reacciona de tres formas diferentes con la hemoglobina y las formas oxidadas de hemo (Pichert y Arnhold, 2015).

\subsubsection{El ClO2- oxida la hemoglobina a metahemoglobina}

Esto puede evidenciarse por el cambio en la absorbancia máxima de $414 \mathrm{~nm}$ a $406 \mathrm{~nm}$. El porcentaje de metahemoglobina aumentó de 0 a $45 \%$ en presencia de WF10 cuando se utilizó una dilución 1: 3 (correspondiente a 21 milimoles / $\mathrm{L}_{\text {de }} \mathrm{ClO}_{2}{ }^{-}$, equivalente a $140 \mathrm{mg} / \mathrm{L}$ ). Cuando se utilizaron diluciones superiores a 1: 200 (correspondientes a 315 micromoles/L, equivalente a $21 \mathrm{mg} / \mathrm{L}$ ), no se produjo metahemoglobinemia (Pichert y Arhold, 2015).

Estos resultados demuestran claramente que la metahemoglobinemia sólo se produce cuando se administran concentraciones elevadas de $\mathrm{ClO}_{2}{ }^{-}$.

\subsubsection{El ClO2- degrada a la metahemoglobina}

Como lo demuestra la disminución continua en la banda de Soret alrededor de $406 \mathrm{~nm}$. Este efecto se obtuvo cuando se utilizó una dilución 1: 500 (correspondiente a $126 \mu$ moles de $\mathrm{ClO}_{2}{ }^{-}$, equivalente a $8,40 \mathrm{mg} / \mathrm{L}$ ). Esta disminución en la formación de metahemoglobina mediada por $\mathrm{ClO}_{2}^{-}$, que también fue informada más tarde por Flemming et al. (2016), el componente $\mathrm{ClO}_{2}^{-}$de WF10 inhibió la hemólisis inducida por hemo de una manera dependiente de la concentración; dichos autores concluyeron que los efectos beneficiosos de WF10 están estrechamente asociados con la inactivación del 
del hemo libre. Además, a una alta concentración de WF10, también se observó la liberación de hierro y la degradación del anillo de porfirina del hemo. Una dilución de fármaco tan baja como $0,1 \%$, correspondiente a una concentración de $\mathrm{ClO}_{2}^{-}$de $62,9 \mu \mathrm{M}(4,19 \mathrm{mg} / \mathrm{L})$, inhibió completamente el efecto hemolítico provocado por $100 \mu \mathrm{M}$ de hemo (Fleming et al., 2016).

Por lo tanto, estos datos sugieren que un $\mathrm{mol}$ de $\mathrm{ClO}_{2}-$ es capaz de inactivar alrededor de dos moles de hemo, por estos mecanismos, el hemo se inactiva y pierde su capacidad de inducir eventos hemolíticos en glóbulos rojos intactos (Flemming et al., 2016). El hemo libre es altamente tóxico para las células y tejidos, especialmente en el bazo, el hígado y el riñón (Schaer et al., 2013) a través de la activación del receptor Toll-like 4, contribuye a la activación de células endoteliales y macrófagos e induce reacciones inflamatorias (Figueiredo et al., 2007; Belcher et al., 2014). La sepsis puede evocar coagulación intravascular diseminada (como la que se encuentra en pacientes con Covid-19), lo que resulta en insuficiencia orgánica múltiple y muerte (Marchandot et al., 2020). La hemo oxigenasa-1 (HO-1) y la hemopexina (HPx) pueden mediar en los mecanismos citoprotectores contra estos efectos deletéreos (Passainte et al., 2015). Sugerimos que el $\mathrm{ClO}_{2}^{-}$derivado del metabolismo del $\mathrm{ClO}_{2}$ podría disminuir la activación de la coagulación intravascular diseminada en pacientes con Covid-19.

Otros investigadores (Pichert y Arnhold, 2015) encontraron que el WF10 (diluido 1: 500) es capaz de reducir eficientemente la producción de especies de hemoglobina citotóxica que pueden aparecer después de una hemólisis excesiva de glóbulos rojos en situaciones patológicas. Dado que se registraron cambios casi idénticos al reemplazar WF10 con $\mathrm{ClO}_{2}^{-}$en la misma concentración, estos investigadores concluyeron que el $\mathrm{ClO}_{2}^{-}$es el ingrediente activo en WF10 (Pichert y Arnhold, 2015). Muy recientemente, un grupo de investigadores descubrió que los niveles elevados de glucosa inducen directamente la replicación viral y la expresión de citocinas pro-inflamatorias. La glucólisis es necesaria para la replicación del SARS-CoV-2 y la producción de ROS mitocondriales (especies reactivas de oxígeno) inducida por este virus y activa al factor inducible por hipoxia (HIF- $\alpha$ ), que a su vez regula al alza los genes glucolíticos y la expresión de IL-1b. Finalmente, demostraron que los monocitos infectados con SARS-CoV2 promueven la disfunción de las células $\mathrm{T}$ y la muerte de las células epiteliales pulmonares. Estos datos pueden explicar por qué los niveles de glucosa en sangre no controlados observados en pacientes diabéticos son un riesgo importante para la gravedad de COVID-19 (Codo et al., 2020). En este sentido, se demostró que el fármaco basado en $\mathrm{ClO}_{2}^{-}$ (WF10) reduce constantemente los valores de hemoglobina glicosilada (A1c) y mejora el control de la glucosa en pacientes diabéticos (Maraprygsavan et al., 2016).

\subsubsection{El ClO2- reduce (inactiva) la hemoglobina ferril (Fe4+)} a metahemoglobina (Fe3+):

La hemoglobina ferril es capaz de oxidar numerosos sustratos biológicos como los lípidos, ácidos nucleicos, proteínas, ami- noácidos y moléculas pequeñas (Everse y Hsia, 1997; Gebicka y Banasiak, 2009). Estas reacciones citotóxicas contribuyen significativamente a la destrucción de tejidos en una serie de enfermedades en las que se produce una hemólisis masiva (Rother et al., 2005). Además de los componentes protectores plasmáticos haptoglobina y hemopexina, que tienen la capacidad de unirse y eliminar especies de hemo libres (Chiabrando et al., 2011), existen otros componentes en la sangre y tejidos adyacentes que actúan como antioxidantes contra la oxidación mediada por la hemoglobina ferril.

El ascorbato, el urato y los flavonoides como la catequina, la quercetina y la rutina reducen la hemoglobina ferril a metahemoglobina (Gebicka y Banasiak, 2009; Giulivi y Davies, 1990; Jia y Alayash, 2008). Pichart y Arnhold (2015) demostraron que el ClO2- (WF10) tiene mayor potencia que los antioxidantes naturales ascorbato y urato para reducir la hemoglobina ferril, especialmente cuando se deriva de la metahemoglobina. Esta evidencia experimental confirma que un oxidante fuerte como el $\mathrm{ClO}_{2}^{-}$es capaz de actuar como antioxidante cuando se administra en concentraciones bajas.

\subsection{Inhibición de la actividad de la mieloperoxidasa mediada por el ClO2-}

Klebanoff (1968) descubrió que la mieloperoxidasa (MPO) es una enzima que contiene un grupo hemo y se encuentra principalmente en neutrófilos y macrófagos. En presencia de superóxido, peróxido de hidrógeno y cloruro, la MPO cataliza la formación de $\mathrm{HOCl}$. El sistema MPO / HOCl juega un papel importante en la destrucción de microbios por los fagocitos. Sin embargo, la mieloperoxidasa también puede liberarse fuera de la célula, aumentando el potencial de daño en la ateroesclerosis, la enfermedad de Alzheimer, la ELA (esclerosis lateral amiotrófica), la esclerosis múltiple, el accidente cerebrovascular, la artritis reumática y la enfermedad de Parkinson (Klebanoff, 2005). El HClO es cinéticamente el oxidante de dos electrones más reactivo producido en cantidades apreciables en nuestro cuerpo. Su reactividad con la mayoría de sustratos excede la del peróxido de hidrógeno, hidroperóxidos y peroxinitrito en varios órdenes de magnitud (Winterbourn, 2008). Además de estos efectos tóxicos directos, el $\mathrm{HOCl}$ puede modular la función y la actividad de varias células inmunes. Por ejemplo, los estudios in vitro demostraron que el $\mathrm{HOCl}$ puede activar el factor nuclear kB (NF-kB) y la fosforilación de tirosina en las células $T$ y $B$, lo que aumenta la señalización de calcio y la producción de factor de necrosis tumoral $\alpha$ (TNF- $\alpha$ ) (Schieven et al., 2002; Schoonbroodt et al., 1997).

Debido a que organizaciones como la OMS y la FDA han afirmado que el $\mathrm{ClO}_{2} / \mathrm{ClO}_{2}^{-}$son altamente tóxicos, casi nadie ha investigado si podrían tener un efecto terapéutico si se administran en concentraciones bajas. Hay muy pocos estudios que hayan investigado los efectos terapéuticos del $\mathrm{ClO}_{2}{ }^{-}$. Los medicamentos llamados NP001 y WF10 están formulados en base a $\mathrm{NaClO}_{2} / \mathrm{ClO}_{2}^{-}$, respectivamente. NP001, una forma estabilizada de $\mathrm{pH}$ ajustado y altamente 
purificada de $\mathrm{NaClO}_{2}$ (clorito de sodio), es una nueva molécula efectora que representa una nueva clase de fármaco para regular la función de los macrófagos inflamatorios tanto en estudios in vitro como in vivo (McGrath et al., 2002). El $\mathrm{ClO}_{2}^{-}$media su efecto antiinflamatorio en los macrófagos mediante la creación de altos niveles intracelulares de taurina cloramina, un factor conocido por regular negativamente las vías inflamatorias inducidas por NF-KB (Joo et al., 2009; Giese et al., 2004). En estudios clínicos previos con otra forma de $\mathrm{ClO}_{2}^{-}$(WF10), esta regulación revierte la inflamación y hace que los macrófagos sistémicos vuelvan a un estado fagocítico normal (McGrath et al., 2002). Recientemente se presentaron los resultados de un ensayo clínico de fase 2 aleatorizado de un nuevo regulador inmunitario, NP001, en la esclerosis lateral amiotrófica (ELA) (NCT01281631). Aunque los resultados del ensayo fueron negativos, mostraron que los pacientes tratados con NP001 cuyos niveles de PCR (proteína $C$ reactiva) basales estaban por encima de la mediana de toda la población aleatorizada tenían una progresión más lenta de ELA que los pacientes que recibieron placebo (Miller et al., 2015).

Existen varias enfermedades relacionadas con la respuesta inflamatoria anormal y la activación de macrófagos: ELA, SIDA, Alzheimer y esclerosis múltiple (Minagar et al., 2002). Se ha demostrado que la activación de macrófagos requiere una alta actividad de mieloperoxidasa intracelular (Rodrigues et al., 2002). Varios estudios mostraron que la formación de $\mathrm{HOCl}$ mediada por MPO puede servir como una fuente principal de daño oxidativo macromolecular (Winterbourn et al., 1992; Hawkins et al., 2003; Kawai et al., 2004). Claramente, la exposición celular a $\mathrm{HOCl}$ puede causar muchos efectos deletéreos al alterar el estado redox celular (Woods et al., 2009), por lo que es importante modular la actividad excesiva de MPO para evitar una mayor producción de $\mathrm{HClO}$.

En este sentido, un estudio seminal demostró que el $\mathrm{ClO}_{2}^{-}$ (WF10) a baja concentración (rango micromolar) inhibe eficazmente la actividad de la mieloperoxidasa (Schempp et al., 2001). Este efecto fue confirmado posteriormente por Jakopitsch et al. (2014). Esta inhibición de la MPO está directamente relacionada con el efecto anti-inflamatorio reportado para este fármaco (Schempp et al., 2001; Giese et al., 2004).

La inhibición de la actividad de la MPO con bajas concentraciones de $\mathrm{ClO}_{2}^{-}$podría tener una aplicación importante en medicina. La resolución de la inflamación depende de que los neutrófilos experimenten apoptosis; sin embargo, esto no siempre sucede y los neutrófilos continúan promoviendo el proceso inflamatorio. Se ha informado de un papel inesperado de la MPO para influir en el destino de los neutrófilos $y$, en consecuencia, en la duración de la inflamación. Al suprimir el programa de muerte celular constitutiva (apoptosis), la MPO prolongó la vida útil de los neutrófilos, retrasando así la resolución de la inflamación (EI Kebir et al., 2008). A partir de estos datos, está claro que la inducción de la apoptosis de neutrófilos mejoraría la resolución de la inflamación. Como el $\mathrm{ClO}_{2}^{-}$es un inhibidor eficaz de la MPO, muchas afecciones inflamatorias agudas y crónicas podrían mitigarse con el uso de esta molécula.

La resistencia a la apoptosis es una característica clave de las células cancerosas y se cree que está regulada por la Snitrosilación inducida por el ión nitrosonio $\left(\mathrm{NO}^{+}\right)$de proteínas apoptóticas como la caspasa 3. El óxido nítrico (NO), producido por la óxido nítrico sintasa inducible (iNOS), es utilizado por la MPO para generar $\mathrm{NO}^{+}$. Se demostró que el $65 \%$ de las muestras de carcinoma de ovario epitelial invasivo analizadas expresan MPO e iNOS en las células neoplásicas, sin expresión en el epitelio ovárico normal (Saed et al., 2010). Estos autores también demostraron que el silenciamiento genético de la MPO o la iNOS indujo significativamente la apoptosis, destacando su papel como un interruptor redox que regula la apoptosis. El ClO2- podría inducir la apoptosis de las células cancerosas basándose en su demostrado efecto inhibidor sobre la actividad de la MPO.

\subsection{La taurina-cloramina neutraliza la toxicidad mediada por el $\mathrm{HClO}$}

Cuando los neutrófilos ingieren y destruyen bacterias, se produce $\mathrm{HClO}$ dentro de la vacuola fagocítica que rodea a las bacterias. Aunque es un poderoso bactericida, también puede ser tóxico porque oxida a varias moléculas biológicas (Kettle et al., 2014). Para evitar esta toxicidad, la taurina reacciona químicamente con el $\mathrm{HClO}$ en los leucocitos para formar taurina-cloramina (tau-clo), un oxidante más estable, menos reactivo y más selectivo que el $\mathrm{HClO}$ (Weiss et al., 1982; Schempp et al., 2001; Giese et al., 2004). Se acepta comúnmente que la tau-clo funciona en sistemas biológicos como un antioxidante general: puede proteger específicamente a las células de la autodestrucción durante los procesos que generan $\mathrm{HClO}$ de manera excesiva (Marcinkiewicz et al., 1995).

El pre-tratamiento de ratas con taurina antes de la exposición aguda al ozono da como resultado una disminución del daño pulmonar inducido por oxidantes (Schuller-Levis et al., 1994). Además, la taurina puede prevenir la lisis de las células epiteliales pulmonares mediada por $\mathrm{HOCl} / \mathrm{OCl}$ al disminuir la cloración de los componentes celulares en lugar de prevenir la oxidación de los grupos sulfidrilo (Cantin, 1994). La tau-clo también inhibe la generación de mediadores inflamatorios producidos por macrófagos, como la proteína inflamatoria de macrófagos-2 (MIP-2), proteína quimio-atrayente de monocitos-1 y 2 (MCP-1 y 2), óxido nítrico, nitritos, prostaglandina E2 (PGE2), factor de necrosis tumoral alfa (TNF- $\alpha$ ) e interleucina 6 (IL-6) (Kim et al., 1996; SchullerLevis et al., 1994; Marcinkiewicz et al., 1995, Barua et al., 2001; Schempp et al., 2001; Quinn et al., 2003). Estos mecanismos de regulación a la baja transforman a los monocitos y macrófagos de un estado pro-inflamatorio a un estado fagocítico basal (Lunetta et al., 2017).

Además, la tau-clo activa el factor nuclear eritroide 2 (Nrf2) (este factor de transcripción regula la expresión inducible de 
numerosos genes para las enzimas desintoxicantes $y$ antioxidantes), aumenta la expresión de la hemo-oxigenasa (HO-1), protege a las células de la muerte causada por el peróxido de hidrógeno $\left(\mathrm{H}_{2} \mathrm{O}_{2}\right)$ y mejora la expresión y las actividades de las enzimas antioxidantes, como la superóxido dismutasa, catalasa y glutatión peroxidasa (Jang et al., 2009). El mecanismo de activación de NRf2 mediado por tau-clo implica un efecto bifásico relacionado con la concentración de $\mathrm{HClO}$. Las concentraciones de $\mathrm{HOCl}$ bajas a moderadas provocan una activación robusta de Nrf2 en macrófagos de ratón cultivados que actúa para restaurar el equilibrio redox. Concentraciones mucho más altas provocan respuestas de estrés de segundo y tercer nivel que potencialmente pueden terminar con la expresión del gen diana del Nrf2 (Woods et al., 2009).

Otros estudios demostraron que los efectos transcripcionales de la tau-clo en genes que regulan la expresión de iNOS (óxido nítrico sintasa inducible) y TNF- $\alpha$ resultan, en parte, de la reducción de la translocación de NF-KB al núcleo de células activadas. La transcripción de los genes iNOS y TNF- $\alpha$ depende críticamente de la vía de señalización del factor de transcripción NF-KB (Murphy, 1999; Liu et al., 2000; Collart et al., 1990). Se sabe que las expresiones genéticas de las citocinas inflamatorias están reguladas por NF-KB (Lloyd y Oppenheim, 1992; Cassatella, 1995). Se ha demostrado que la tau-clo inhibe la producción de citocinas inflamatorias (Marcinkiewicz et al., 1998; Kontny et al., 2000); el mecanismo molecular de la inhibición de la activación de NFkB inducida por la tau-clo consiste en la oxidación de $\mathrm{IkB} \alpha$ en metionina45.

\subsection{La taurina-cloramina contribuye a la resolución de la inflamación}

La información antes mencionada nos permite concluir que la función biológica de la tau-clo en el neutrófilo no es solo la reducción de la citotoxicidad del $\mathrm{HClO}$, sino también la mitigación de una reacción inflamatoria excesiva (Kanayama et al., 2002). Después de destruir a los microbios, los neutrófilos maduros sufren una muerte celular programada constitutiva (apoptosis) que los hace insensibles a los quimioatrayentes y permite su reconocimiento y eliminación por los macrófagos carroñeros (Savill et al., 1989), lo que conduce a la resolución de la inflamación (Savill et al., 2002). Sin embargo, la supervivencia y la apoptosis de los neutrófilos están profundamente influenciadas por el entorno inflamatorio y la supresión de la apoptosis de los neutrófilos provoca una inflamación crónica (Simon, 2003; Gilroy et al., 2004). De hecho, se detectó una marcada disminución en la apoptosis de neutrófilos en pacientes con enfermedades inflamatorias (Matute-Bello et al., 1997; Keel et al., 1997). La regulación de la apoptosis de neutrófilos durante la fase aguda de la inflamación está menos definida, sin embargo, es fundamental para la expresión y resolución óptimas de la inflamación.

Trabajos recientes confirmaron que la tau-clo contribuye a la resolución de la inflamación estimulando la eferocitosis (engullimiento fagocítico de neutrófilos apoptóticos por macrófagos) (Kim et al., 2015) e inhibiendo la liberación de MPO por parte de los neutrófilos (Kim et al., 2020). El aumento en el nivel intracelular de MPO regula negativamente la expresión de MIP-2 (una quimiocina involucrada en el reclutamiento de neutrófilos en el sitio de inflamación), contribuyendo así a un mecanismo de retroalimentación negativa que asegura que los neutrófilos no generen una respuesta inflamatoria excesiva (Kim et al., 2020). Durante la eferocitosis, los macrófagos aumentan su secreción de la citoquina antiinflamatoria e inmunorreguladora interleucina 10 (IL-10) y disminuyen la secreción de las citocinas pro-inflamatorias factor de necrosis tumoral-a (TNF-a), IL-1 e IL-12 (Voll et al. 1997). La eferocitosis estimulada por la tau-clo derivada del metabolismo del $\mathrm{ClO}_{2}^{-}$debería estudiarse en profundidad, ya que se ha observado una eferocitosis alterada en muchas enfermedades inflamatorias y autoinmunes humanas, incluyendo la fibrosis quística, enfermedad pulmonar obstructiva crónica, asma, fibrosis pulmonar idiopática, artritis reumatoide, lupus eritematoso sistémico, glomerulonefritis, y aterosclerosis (Vandivier et al., 2006).

\subsection{El ClO2- restaura el equilibrio redox a través de mecanismos horméticos}

$\mathrm{El} \mathrm{ClO} 2^{-}$es capaz de inducir efectos protectores a través de la hormesis, que es un fenómeno de dosis-respuesta que se caracteriza por la estimulación a concentraciones bajas y la inhibición a concentraciones altas (Calabrese y Baldwin, 2001; Mattson, 2008; Calabrese y Baldwin, 2002; Calabrese y Mattson, 2017). La hormesis puede ocurrir como resultado de la estimulación directa o como una respuesta de compensación excesiva después de una interrupción de la homeostasis o la inducción de una toxicidad baja a moderada. (Calabrese, 2008; Calabrese, 2013). Como ya se mencionó anteriormente, las concentraciones bajas de $\mathrm{ClO}_{2}^{-}$pueden inhibir la producción de metahemoglobina, inactivar a la hemoglobina ferril e inhibir la excesiva actividad de la MPO. En términos generales, estos efectos protectores son inducidos indirectamente por el $\mathrm{ClO}_{2}^{-}$, estimulando la producción de enzimas antioxidantes que protegen a los eritrocitos del daño oxidativo. Además, el $\mathrm{ClO}_{2}^{-}$modula indirectamente la síntesis del Nrf2, al inhibir la producción excesiva de $\mathrm{HClO}$ (Woods et al., 2009). Aunque no encontramos efectos bifásicos mediados por el $\mathrm{ClO}_{2}-$, una estimulación indirecta podría resultar en el fortalecimiento de los sistemas antioxidantes del cuerpo, equilibrando así el balance redox para proteger contra el daño oxidativo.

\section{Conclusión}

Hemos encontrado que la principal molécula bioactiva (derivada del metabolismo del $\mathrm{ClO}_{2}$ ) dentro del cuerpo es el $\mathrm{ClO}_{2}^{-}$, ya que, debido a su alta reactividad química, es poco probable que el $\mathrm{ClO}_{2}$ permanezca en el cuerpo sin reducirse durante mucho tiempo después de la ingestión. $\mathrm{El} \mathrm{ClO}_{2}^{-}$tiene una alta permanencia en plasma y tejidos después de su absorción, antes de su eliminación por vía urinaria y fecal, mayoritariamente en forma de cloruro. La actividad antiviral de $\mathrm{ClO}_{2}$ y $\mathrm{ClO}_{2}^{-}$se ha descrito en pruebas in vitro e in vivo, y se basa en la capacidad de oxidar y desnaturalizar las proteínas de la cápside del virus. El hecho de que $\mathrm{ClO}_{2} / \mathrm{ClO}_{2}^{-}$no sean tóxicos si se 
ingieren a bajas concentraciones sugiere una interesante aplicación terapéutica. Los estudios in vitro han demostrado que el $\mathrm{ClO}_{2}$ puede inactivar el virus de la influenza humana, el virus del sarampión y el virus del herpes (Sanekata et al., 2010). Otros investigadores demostraron que el $\mathrm{ClO}_{2}$ es capaz de destruir el virus de la poliomielitis, la hepatitis A, el VIH-1 y el coronavirus que causó el SARS (citado en Miura y Shibata, 2010). La ingestión oral de soluciones acuosas de $\mathrm{ClO}_{2}$ en concentraciones bajas (0,3-0,9 mg / kg / día) podría utilizarse para la prevención y el tratamiento de infecciones virales mortales, como la influenza, el COVID-19 y el SIDA.

Los procesos de acción inmunomoduladora más estudiados son la interacción con hemoproteínas de los glóbulos rojos, en particular la metabolización del exceso de metahemoglobina y la regulación de la actividad enzimática de la MPO en neutrófilos y macrófagos, transformando a los monocitos y macrófagos de un estado pro-inflamatorio a un estado fagocítico basal. Un intermedio clave en el control inflamatorio es la generación de tau-clo inducida por el $\mathrm{ClO}_{2}{ }^{-}$ (Chinake y Simoyi, 1997; Schempp et al., 2001; Giese et al., 2004) como un agente oxidante estable y moderado, que neutraliza el exceso de $\mathrm{HClO}$, mitiga la reacción inflamatoria excesiva (Giese et al., 2004) y contribuye a la resolución de la respuesta inflamatoria al inducir la apoptosis de neutrófilos (Kim et al., 2020).

Por tanto, la tau-clo representa el producto funcional más relevante formado bajo la influencia del $\mathrm{ClO}_{2}^{-}$(WF10) (Schempp et al.,2001; Giese et al., 2004). De hecho, un experimento in vitro mostró que el WF10 inhibe la activación pro-inflamatoria del tipo M1 en macrófagos; los resultados sugirieron que el $\mathrm{ClO}_{2}^{-}$es el principio activo en WF10 ya que provocó los mismos cambios que el WF10 (Schönberg et al., 2016). Dado que el $\mathrm{ClO}_{2}^{-}$es también el principal producto del metabolismo del $\mathrm{ClO} 2$ después de su ingestión oral, sugerimos que el uso de soluciones acuosas de $\mathrm{ClO}_{2}$ en bajas concentraciones podría inducir los mismos efectos terapéuticos que el WF10.

Estos efectos inmunomoduladores podrían tener relevancia clínica para el tratamiento de algunas enfermedades, como el Alzheimer, Parkinson, SIDA, artritis reumatoide y la esclerosis lateral amiotrófica. El análisis de la literatura también reveló la existencia de efectos opuestos mediados por el $\mathrm{ClO}_{2}$, un efecto estimulante o beneficioso a bajas concentraciones y un efecto tóxico o dañino en altas concentraciones, de acuerdo con los principios horméticos. Esto contradice al paradigma aceptado en torno al $\mathrm{ClO}_{2}$ y $\mathrm{ClO}_{2}^{-}$, considerados solamente como agentes tóxicos. 


\section{Literatura citada}

-Abdel-Rahman, M.S., Couri, D., Bull, R.J. (1979a). Kinetics of $\mathrm{ClO} 2$ and $\mathrm{ClO} 3$ in drinking water on blood glutathione and hemolysis in rat and chicken. J Environ Pathol Toxicol 3:431-449. PMID: 547024.

- Abdel-Rahman, M.S., Couri, D., \& Jones, J.D. (1979b). Chlorine dioxide metabolism in rat. Journal of environmental pathology and toxicology, 3(1-2), 421-430.

- Abdel-Rahman, M.S., Couri, D., Bull, R.J. (1982). Metabolism and pharmacokinetics of alternate drinking water disinfectants. Environ Health Perspect 46:19-23. doi: 10.1289/ehp.824619

- Abdel-Rahman, M.S., Couri, D., Bull, R.J. (1984). The kinetics of chlorite and chlorate in the rat. J Am Coll Toxicol 3:261-267. https://doi.org/10.3109/10915818409009080

- Barua, M., Liu, Y., Quinn, M.R. (2001). Taurine chloramine inhibits inducible nitric oxide synthase and TNF-alpha gene expression in activated alveolar macrophages: decreased NF-kappaB activation and IkappaB kinase activity. J Immunol 167:2275-2281

- Bhakta-Guha, D., and Efferth, T. (2015). Hormesis: Decoding Two Sides of the Same Coin. Pharmaceuticals (Basel, Switzerland), 8(4), 865-883. https://doi.org/ 10.3390/ph8040865

- Belcher, J.D, Chen, C, Nguyen J, Milbauer L, Abdulla F, Alayash A.I, Smith A, Nath, K.A, Hebbel, R.P, Vercelotti, G.M. (2014). Heme triggers TLR4 signaling leading to endothelial cell activation and vaso-occlusion in murine sickle cell disease. Blood 123:377-390. DOI: 10.1182/ blood-2013-04-495887

-Bercz, J.P., Jones, L., Garner, L., Murray, D., Ludwig, D.A., \& Boston, J. (1982). Subchronic toxicity of chlorine dioxide and related compounds in drinking water in the nonhuman primate. Environmental health perspectives, 46, 47-55. https://doi.org/ 10.1289/ehp.824647

- Calabrese, E.J., Baldwin, L.A. Inorganics and hormesis. Crit Rev Toxicol. (2003);33(3-4):215-304. doi: 10.1080/713611040. PMID: 12809427.

- Calabrese, E. J. (2008). Hormesis and medicine. British journal of clinical pharmacology, 66(5), 594-617. https:// doi.org/ 10.1111/j.1365-2125.2008.03243.x

- Calabrese, V., Cornelius, C., Trovato, A., Cavallaro, M., Mancuso, C., Di Rienzo, L., Condorelli, D., De Lorenzo, A., \&

- Calabrese, E. J. (2010). The hormetic role of dietary antioxidants in free radical-related diseases. Current pharmaceutical design, 16(7), 877-883. https:// doi.org/10.2174/138161210790883615.

- Calabrese, E. J. (2013). Hormetic mechanisms. Critical reviews in toxicology, 43(7), 580-606. https://doi.org/ 10.3109/10408444.2013.808172

- Calabrese, E.J. (2014). Hormesis: From mainstream to therapy. J. Cell Commun. Signal. 8:289-291. doi: 10.1007/ s12079-014-0255-5

- Calabrese, E.J, and Baldwin, L.A. (2001). Hormesis: Ushaped dose responses and their centrality in toxicology. Trends Pharmacol Sci.; 22:285-2 91. doi: 10.1016/ s0165-6147(00)01719-3

- Calabrese, E.J, and Baldwin, L.A. (2002). Defining hormesis. Hum Exp Toxicol. 21:91-97. Doi: 10.1191/0960327102ht217oa
- Calabrese, E.J., and Mattson, M.P. (2017). How does hormesis impact biology, toxicology, and medicine? NPJ of disease, 3, 13. https://doi.org/ 10.1038/ s41514-017-0013-z

- Cantin A.M. (1994). Taurine modulation of hypochlorous acid-induced lung epithelial cell injury in vitro. Role of anion transport. The Journal of clinical investigation, 93(2), 606-614. https://doi.org/ 10.1172/ $\mathrm{JCl} 117013$

- Cassatella, M.A. (1995). The production of cytokines by polymorphonuclear neutrophils. Immunology today, 16(1), 21-26. https://doi.org/ 10.1016/0167-5699(95)80066-2

- Chiabrando, D, Vinchi, F, Fiorito, V, Tolosano, E. (2011). In: F. Veas (Ed.), Acute Phase Proteins -Regulation and Functions of Acute Phase Proteins, Rijeka, pp. 261e288.

- Chinake, C.R. and Simoyi, R.H. (1997). Oxyhalogen -Sulfur Chemistry: Oxidation of Taurine by Chlorite in Acidic Medium. The Journal of Physical Chemistry B. 101 (7), 1207-1214. https://doi.org/10.1021/jp963067a

- Codo, A. C., Davanzo, G. G., Monteiro, L. B., et al.(2020). Elevated Glucose Levels Favor SARS-CoV-2 Infection and Monocyte Response through a HIF-1 $\alpha /$ GlycolysisDependent Axis. Cell metabolism, S1550-4131(20)30365-X. Advance online publication. https:// 10.1016/j.cmet.2020.07.007

- Collart, M.A., Baeuerle, P., Vassalli, P. (1990). Regulation of tumor necrosis factor $\alpha$ transcription in macrophages: involvement of four $\mathrm{kB}$-like motifs and of constitutive and inducible forms of NF-kB. Mol. Cell. Biol. 10: 1498. Doi: $10.1128 / \mathrm{mcb} \cdot 10.4 .1498$

- Couri, D., and Abdel-Rahaman, M.S. (1979). Effect of chlorine dioxide and metabolites on glutathione dependent system in rat, mouse and chicken blood. J. Environ. Pathol. Toxicol. 3(1,2), 451-460. PMID: 547025

-Day, R.M., and Suzuki Y.J. (2006). Cell proliferation, reactive oxygen and cellular glutathione. DoseResponse. (2006); 3:425-442. doi: 10.2203/doseresponse.003.03.010

- El Kebir, D., József, L., Pan, W., \& Filep, J. G. (2008). Myeloperoxidase delays neutrophil apoptosis through CD11b/CD18 integrins and prolongs inflammation. Circulation research, 103(4), 352-359. https:// doi.org/10.1161/01.RES.0000326772.76822.7a Everse,

- J., \& Hsia, N. (1997). The toxicities of native and modified hemoglobins. Free radical biology \& medicine, 22(6), 1075-1099. DOI: 10.1016/ s0891-5849(96)00499-6

- Figueiredo, R.T, Fernandez, P.L., Mourao-Sa, D.S., Porto, B.N, Dutra, F.F., Alves, L.S., Oliviera, M.F., Oliviera, P.L., Graca-Souza, A.V., Bozza, M.T. (2007). Characterization of heme as activator of toll-like receptor 4 . J Biol Chem. 282:20221-20229. 10.1074/jbc.M610737200 Flemmig,

- J., Schlorke, D., Kühne, F. W., \& Arnhold, J.(2016). Inhibition of the heme-induced hemolysis of red blood cells by thechlorite-based drug WF10. Free radical research, 50(12), 1386-1395. https://doi.org/ 10.1080/10715762.2016.1252838 
- Gebhardtova, A., Vavrinec, P., Vavrincova-Yaghi, D., Seelen, M., Dobisova, A., Flassikova, Z., Cikova, A., Henning, R. H., \& Yaghi, A. (2014). A case of severe chlorite poisoning successfully treated with early administration of methylene blue, renal replacement therapy, and red blood cell transfusion: case report. Medicine, 93(9), e60. https://doi.org/ 10.1097/ MD.0000000000000060

- Gebicka, L., and Banasiak, E. (2009). Flavonoids as reductants of ferryl hemoglobin. Acta biochimica Polonica, 56(3), 509-513. http://www.actabp.pl/ pdf/3_2009/509.pdf

- Giese, T., McGrath, M. S., Stumm, S., Schempp, H., Elstner, E., \& Meuer, S. C. (2004). Differential effects on innate versus adaptive immune responses by WF10. Cellular immunology, 229(2), 149-158. Doi: 10.1016/ j.cellimm.2004.08.001

- Gill, M.W., Swanson, M.S., Murphy, S.R., \& Bailey, G.P. (2000). Two-generation reproduction and developmental neurotoxicity study with sodium chlorite in the rat. Journal of applied toxicology: JAT, 20(4), 291303. Doi:10.1002/1099-1263(200007/08)20:4<291::aidjat658>3.0.co;2-y

- Gilroy, D.W., Lawrence, T., Perretti, M., Rossi, A.G. (2004). Inflammatory resolution: new opportunities for drug discovery. Nat. Rev. Drug Discov. 3. Doi: 10.1038/ nrd1383

- Giulivi, C., and Davies, KJA. (1990). A novel antioxidant role for haemoglobin. The comproportionation of ferrylhemoglobin with oxyhemoglobin. J Biol Chem 265: 19453-19460.

- Harrington, R., Gates, D., Ramano, R.R. (1986): A review of the uses, chemistry and health effects of chlorine dioxide and chlorite ion. Final Report, American Chemical Council, Washington, DC.

- Hati, S., and Bhattacharyya, S. (2020). Impact of ThiolDisulfide Balance on the Binding of Covid-19 Spike Protein with Angiotensin-Converting Enzyme 2 Receptor. ACS omega, 5(26), 16292-16298. https://doi: 10.1021/acsomega.0c02125

- Hawkins, C.L., Pattison, D.I., Davies, M.J., (2003). Hypochlorite-induced oxidation of amino acids, peptides and proteins. Amino Acids 25, 259-274. 10.1007/s00726-003-0016-x

- Heffernan, W.P., Guion, C., and Bull, R.J. (1979). Oxidative damage to the erythrocyte induced by sodium chlorite, in vivo. J. Environ. Pathol. Toxicol. 2: 1487-1499. PMID: 528853.

- Hill, A.S., Haut, Jr., and Wintrose, M.M. (1964). Role of nonhemoglobin protein and reduced glutathione in the protection of hemoglobin from oxidation in vitro. J. Clin. Invest. 43, 17-26. doi: 10.1172/JCl104889

- Huang, S.S., and Zheng, R.L. (2006). Biphasic regulation of angiogenesis by reactive oxygen species. Die Pharmazie, 61(3), 223-229. PMID: 16599264. Insignares-

- Carrione, E., Bolano-Gómez, B., Kalcker, A.L.(2020). Chlorine Dioxide in COVID-19: Hypothesis about the Possible Mechanism of Molecular Action in SARSCoV-2. Jounal of Molecular and Genetic Medicine, Volume 14, Issue 5.
- Insignares-Carrione, E, Bolano Gómez, B, Andrade, Y., Callisperis, P, et al. (2021). Determination of the Effectiveness of Chlorine Dioxide in the Treatment of COVID 19. Journal of Molecular and Genetic Medicine, Volume 15, Issue 1. - Jakopitsch, C., Spalteholz, H., Furtmüller, P.G., Arnhold, J., Obinger, C. (2008). Mechanism of reaction of horseradish peroxidase with chlorite and chlorine dioxide. J Inorg Biochem.102:108-128. Doi: 10.1016/j.jinorgbio.2014.02.010

- Jakopitsch, C., Pirker, K.F., Flemmig, J., Hofbauer, S., Schlorke, D., Furtmüller, P.G. et al. (2014). Mechanism of reaction of chlorite with mammalian heme peroxidases. J Inorg Biochem; 135:10-1. Doi: 10.1016/ j.jinorgbio.2014.02.010

- Jang, J.S., Piao, S., Cha, Y. N., \& Kim, C. (2009). Taurine Chloramine Activates Nrf2, Increases HO-1 Expression and Protects Cells from Death Caused by Hydrogen Peroxide. Journal of clinical biochemistry and nutrition, 45(1), 37-43. https:// doi: 10.3164/ jcbn.08-262

- Jia, Y., and Alayash, A. I. (2008). Effects of (-)epigallocatechin gallate on the redox reactions of human hemoglobin. Free radical biology \& medicine, 45(5), 659-666. https://doi.org/ 10.1016/ j.freeradbiomed.2008.05.010

- Joo, K., Lee, Y., Choi, D., Han, J., Hong, S., Kim, Y.M., et al. (2009). An anti-inflammatory mechanism of taurine conjugated 5-aminosalicylic acid against experimental colitis: taurine chloramine potentiates inhibitory effect of 5-aminosalicylic acid on IL-1beta-mediated NFkappaB activation. European Journal of Pharmacology, 618:91-7. Doi: 10.1016/ j.ejphar.2009.07.009

- Kanayama, A., Inoue, J., Sugita-Konishi, Y., Shimizu, M., \& Miyamoto, Y. (2002). Oxidation of Ikappa Balpha at methionine 45 is one cause of taurine chloramine-induced inhibition of NF-kappa B activation. The Journal of biological chemistry, 277(27), 24049-24056. https://doi.org/ 10.1074/ jbc.M110832200

- Kawai, Y., Morinaga, H., Kondo, H., Miyoshi, N., Nakamura, Y., Uchida, K., Osawa, T., (2004). Endogenous formation of novel halogenated 2'deoxycytidine. Hypohalousacid-mediated DNA modification at the site of inflammation. J. Biol. Chem. 279,51241-51249. https://doi.org/10.1074/ jbc.M408210200

- Keel, M., Ungethum, U., Steckholzer, U., Niederer, E., Hartung, T., Trentz, O.and Ertel, W. (1997). Interleukin-10 counterregulates proinflammatory cytokine-induced inhibition of neutrophil apoptosis during sepsis. Blood 90: 3356 -3363. https:// doi.org/10.1182/blood.V90.9.3356

- Kettle, A.J., Albrett, A.M., Chapman, A.L., Dickerhof, N., Forbes, L.V., Khalilova, I., \& Turner, R. (2014). Measuring chlorine bleach in biology and medicine. Biochimica et biophysica acta, 1840(2), 781-793. https://doi.org/ 10.1016/j.bbagen.2013.07.004 
-Kim, C., Park, E. Quinn, M.R, Schuller-Levis, G. (1996). The production of superoxide anion and nitric oxide by cultured murine leukocytes and the accumulation of TNF-alpha in the conditioned media is inhibited by taurine chloramine. Immunopharmacology; 34:89-95 - Kim, W., Kim, H.U., Lee, H.N., et al. (2015). Taurine Chloramine Stimulates Efferocytosis Through Upregulation of Nrf2-Mediated Heme Oxygenase-1Expression in Murine Macrophages: Possible Involvement of Carbon Monoxide. Antioxidants \& redox signaling, 23(2), 163-177. https://doi.org/ 10.1089/ars.2013.5825

- Kim, D.G., Kwon, Y.M., Kang, I.S. et al. (2020). Taurine chloramine selectively regulates neutrophil degranulation through the inhibition of myeloperoxidase and upregulation of lactoferrin. Amino Acids 52, 1191-1199 (2020). Doi: 10.1007/ s00726-020-02886-5

- Klebanoff, S.J., and Luebke, R.G. (1965) The antilactobacillus system of saliva. Role of salivary peroxidase. Proc. Soc. Exp. Biol. Med. 118, 483- 486. Doi:

10.3181/00379727-118-29882

- Klebanoff, S.J. (1968). Myeloperoxidase-halidehydrogen peroxide antibacterial system. J Bacteriol 95:2131-2138

- Klebanoff S.J. (2005). Myeloperoxidase: friend and foe. Journal of leukocyte biology, 77(5), 598-625. https:// doi.org/

10.1189/jlb.1204697

- Kontny, E., Szczepanska, K., Kowalczewski, J., Kurowska, M., Janicka, I., Marcinkiewicz, J., Maslinski, W. (2000). The mechanism of taurine chloramine inhibition of cytokine (interleukin-6, interleukin-8) production by rheumatoid arthritis fibroblast-like synoviocytes. Arthritis Rheum 43:2169-2177 - Kouda, K., and Iki, M. (2010). Beneficial effects of mild stress (hormetic effects): Dietary restriction and health. J. Physiol. Anthropol. 29:127-132. doi: 10.2114/jpa2.29.127

- Lin, J.L., and Lim, P.S. (1993). Acute sodium chlorite poisoning associated with renal failure. Renal failure, 15(5), 645-648. https://doi.org/ $10.3109 / 08860229309069417$

- Lloyd, A.R., and Oppenheim, J.J. (1992). Poly's lament: the neglected role of the polymorphonuclear neutrophil in the afferent limb of the immune response. Immunology today, 13(5), 169-172. https:// doi.org/ 10.1016/0167-5699(92)90121-M - Liu, H., Sidiropoulos, Song, P.G., Pagliari, L.J., Birrer, M.J., Stein, B., Anrather, J.,Pope. R.M.(2000). TNF- $\alpha$ gene expression in macrophages: regulation by NF-KB is independent of c-Jun or C/EBP $\beta$. J. Immunol. 164: 4277. Doi: 10.4049/jimmunol.164.8.4277 - Lubbers, J.R., Chauan, S., \& Bianchine, J.R. (1982). Controlled clinical evaluations of chlorine dioxide, chlorite and chlorate in man. Environmental health perspectives, 46, 57-62. doi: 10.1289/ehp.824657 - Lunetta C, Lizio A, Maestri E, et al. (2017). Serum CReactive Protein as a Prognostic Biomarker in Amyotrophic Lateral Sclerosis. JAMA Neurol.;74(6):660-667. doi: 10.1001/ jamaneurol.2016.6179
- McGrath, M.S, Kahn, J.O., Herndier, B.G. (2002). Curr. Opin. Investig. Drugs 3, 365-373. PMID: 12054081

- Maraprygsavan, P., Mongkolsuk, J., Arnhold, J., \& Kuehne, F. W. (2016). The chlorite-based drug WF10 constantly reduces hemoglobin A1c values and improves glucose control in diabetes patients with severe foot syndrome. Journal of clinical \& translational endocrinology, 4, 53-58. https:// doi.org/ 10.1016/j.jcte.2016.05.001 - Marchandot, B., Sattler, L., Jesel, L., Matsushita, K., Schini-Kerth, V., Grunebaum, L., \& Morel, O. (2020). COVID-19 Related Coagulopathy: A Distinct Entity? Journal of clinical medicine, 9(6), 1651. https:// doi.org/10.3390/jcm9061651

- Marcinkiewicz, J., Grabowska, A., Bereta, J., \& Stelmaszynska, T. (1995). Taurine chloramine, a product of activated neutrophils, inhibits in vitro the generation of nitric oxide and other macrophage inflammatory mediators. Journal of leukocyte biology, 58(6), 667-674. https://doi.org/ 10.1002/jlb.58.6.667

- Marcinkiewicz, J., Grabowska, A., Bereta, J., Bryniarski, K., \& Nowak, B. (1998). Taurine chloramine down-regulates the generation of murine neutrophil inflammatory mediators. Immunopharmacology, 40(1), 27-38. https:// doi.org/ 10.1016/s0162-3109(98)00023-x Martins,

- I., Galluzzi, L., Kroemer, G. Hormesis, cell death and aging. Aging. 2011; 3:821-828. Doi: 10.18632/aging.100380

- Mattson, M.P. (2008). Hormesis defined. Age Res Rev.7:1-7. doi: 10.1016/j.arr.2007.08.007

- Matute-Bello, G., Liles, W.C., Radella, F., Steinberg, K.P., Ruzinski, J., Jonas, M., Chi, E., Hudson, L.D., and Martin, T.R. (1997). Neutrophil apoptosis in the acute respiratory distress syndrome. Am. J. Respir. Crit. Care Med. 156:1969 -1977. Doi: 10.1164/ ajrccm.156.6.96-12081

- Menendez, J.A., Joven, J., Aragonés, G., BarrajónCatalán, E., Beltrán-Debón, R., Borrás-Linares, I., Camps, J., Corominas-Faja, B., Cufí, S., FernándezArroyo, S., et al. (2013). Xenohormetic and antiaging activity of secoiridoid polyphenols present in extra virgin olive oil: A new family of gerosuppressant agents. Cell Cycle Georget. Tex. 12:555-578. doi: 10.4161/cc.23756 - Miller, R.G., Zhang, R., Block, G., et al. (2014). NP001 regulation of macrophage activation markers in ALS: a phase I clinical and biomarker study. Amyotroph Lateral Scler Frontotemporal Degener 15: 601-609. Doi: 10.3109/21678421.2014.951940

- Miller, R.G., Block, G., Katz, J.S., Barohn, R.J., Gopalakrishnan, V., Cudkowicz, M., Zhang, J.R., McGrath, M.S., Ludington, E., Appel, S.H., Azhir, A. (2015). Randomized phase 2 trial of NP001-a novel immune regulator: Safety and early efficacy in ALS. Neurol Neuroimmunol Neuroinflamm Apr 9;2(3). DOI: $10.1212 / N X I .0000000000000100$ 
- Minagar, A., Shapshak, P., Fujimura, R., Ownby, R., Heyes, M., \& Eisdorfer, C. (2002). The role of macrophage/microglia and astrocytes in the pathogenesis of three neurologic disorders: HIVassociated dementia, Alzheimer disease, and multiple sclerosis. Journal of the neurological sciences, 202(1-2), 13-23. https://doi.org/ 10.1016/ s0022-510x(02)00207-1

- Miura, T., and Shibata, T. (2010). Antiviral Effect of Chlorine Dioxide against Influenza Virus and Its Application for Infection Control. The Open Antimicrobial Agents Journal, 2. https:// benthamopen.com/contents/pdf/TOANTIMJ/ TOANTIMJ-2-71.pdf

- Moore, G.S., and Calabrese, E.J. (1982). Toxicological effects of chlorite in the mouse. Environmental health perspectives, 46, 31-37. DOI: 10.1289/ehp.824631

- Murphy, W.J. (1999). Transcriptional regulation of the genes encoding nitric oxide synthase. J. Laskin, Jr, and D. Laskin, Jr, eds. Molecular and Cellular Biology of Nitric Oxide Dekker, New York, p.1. Ogata, N. (2007). Denaturation of protein by chlorine dioxide: oxidative modification of tryptophan and tyrosine residues. Biochemistry, 46(16), 4898-4911. https://doi.org/ 10.1021/ bi061827u

- Ogata, N. (2012). Inactivation of influenza virus haemagglutinin by chlorine dioxide: oxidation of the conserved tryptophan 153 residue in the receptorbinding site. The Journal of general virology, 93 (Pt 12),2558-2563.https://doi.org/10.1099/ vir.0.044263-0

- Ogata, N., and Shibata, T. (2008). Protective effect of low-concentration chlorine dioxide gas against influenza A virus infection. The Journal of general virology, 89(Pt 1), 60-67. DOI: 10.1099/ vir.0.83393-0

- Passainte, S. Hassaan, Radwa A. Mehanna, Abeer E. Dief. (2015). The Potential Role of Hemopexin and Heme Oxygenase-1 Inducer in a Model of Sepsis, Physiology Journal, vol. 2015, Article ID 208485, 10 pages. https://doi.org/10.1155/2015/208485 Pichert A, and Arnhold J. (2015). Interaction of the chlorite-based drug WF10 with hemoglobin,methemoglobin and ferryl hemoglobin. Arch Biochem Biophys ;585: 82-89. Doi: 10.1016/ j.abb.2015.09.009

- Quinn, M.R., Barua, M., Liu, Y., Serban, V. (2003). Taurine Chloramine Inhibits Production of Inflammatory Mediators and iNOS Gene Expression in Alveolar Macrophages; a Tale of Two Pathways: Part I, NF-kB Signaling. In: Lombardini J.B., Schaffer S.W., Azuma J. (eds) Taurine 5. Advances in Experimental Medicine and Biology, vol 526. Springer, Boston, MA. https://doi.org/ 10.1007/978-1-4615-0077-3_42.

- Raffanti, S.P., Schaffner, W., Federspiel, C.F., Blackwell, R.B., Ching, O. A., \& Kühne, F. W. (1998). Randomized, double-blind, placebo-controlled trial of the immune modulator WF10 in patients with advanced AIDS. Infection, 26(4), 202-207. https:// doi.org/ 10.1007/BF02962364
- Rattan, S.I.S. (2006). Hormetic modulation of aging and longevity by mild heat stress. DoseResponse. 3:533-546. doi: 10.2203/doseresponse.003.04.008

- Richardson, R.B. (2009). Ionizing radiation and aging: rejuvenating an old idea. Aging.1:887-902. Doi: $\quad$ 10.18632/aging.100081

- Rhee, S.G., and Lee, S.K. (2017). Differential Function of Catalase, Glutathione Peroxidase, And Peroxiredoxin. In: Mouse Red Blood Cells, Free Radical Biology and Medicine. Volume 112, Supplement $1 . \quad$ https://doi.org/10.1016/ j.freeradbiomed.2017.10.354

- Rodrigues, M.R., Rodriguez, D., Russo, M., \& Campa, A. (2002). Macrophage activation includes high intracellular myeloperoxidase activity. Biochemical and biophysical research communications, 292(4), 869-873. https:// 10.1006/bbrc. 2002.6724

- Rother, R.P., Bell, L., Hillmen, P., \& Gladwin, M.T. (2005). The clinical sequelae of intravascular hemolysis and extracellular plasma hemoglobin: a novel mechanism of human disease. JAMA, 293(13), 1653-1662. https://doi.org/ 10.1001/ jama.293.13.1653

- Saed, G.M., Ali-Fehmi, R., Jiang, Z.L., Fletcher, N.M., Diamond, M.P., Abu-Soud, H.M., \& Munkarah, A.R. (2010). Myeloperoxidase serves as a redox switch that regulates apoptosis in epithelial ovarian cancer. Gynecologic oncology, 116(2), 276-281. Doi: 10.1016/ j.ygyno.2009.11.004

- Sanekata, T., Fukuda, T., Miura, T., Morino, H., Lee, C., Maeda, K., Araki, K., Otake, T., Kawahata, T., \& Shibata, T. (2010). Evaluation of the antiviral activity of chlorine dioxide and sodium hypochlorite against feline calicivirus, human influenza virus, measles virus, canine distemper virus, human herpesvirus, human adenovirus, canine adenovirus and canine parvovirus. Biocontrol science, 15(2), 45-49. Doi: 10.4265/bio.15.45

- Savill, J.S., Wyllie, A.H., Henson, J.E., Walport, M.J., Henson, P.M., and Haslett, J.C. (1989). Macrophage phagocytosis of aging neutrophils in inflammation: programmed cell death in the neutrophil leads to its recognition by macrophages. J. Clin. Invest. 83: 865- 875. Doi: 10.1172/JCI113970

- Savill, J.I., Dransfield, Gregory, C., and Haslett, C. (2002). A blast from the past: clearance of apoptotic cells regulates immune responses. Nat. Rev. Immunol. 2:965-975. Doi: 10.1038/nri957 Schaer, D.J., Buehler, P.W., Alayash, A.I., Belcher, J.D., Vercelotti, G.M. (2013). Hemolysis and free hemoglobin revisited: exploring hemoglobin and hemin scavengers as a novel class of therapeutic proteins. Blood 121:1276-1284. Doi: 10.1182/ blood-2012-11-451229

- Schempp H, Reim M, Dornisch K, Elstner E. (2001). Chlorite-hemoprotein interaction as key role for the pharmacological activity of the chlorite-based drug WF10. Drug Res 51:3-11. Doi: 


\subsection{5/s-0031-1300079}

- Schieven, G.L., de Fex, H., and Stephenson, L. (2002). Hypochlorous acid activates tyrosine phosphorylation signal pathways leading to calcium signaling and TNF-alpha production. Antioxid Redox Signal 4: 501-507. Doi: 10.1089/15230860260196308

- Schönberg, M., Schlorke, D., Arnhold, J. (2016). Effects of WF10 on Glycosaminoglycan Sulphation in Proinflammatory Monocytes and Macrophages. From the Edited Volume: Flow Cytometry-Select Topics. Edited by Ingrid Schmid. DOI: 10.5772/60862.

- Schoonbroodt, S., Legrand-Poels, S., BestBelpomme, M., and Piette, J. (1997). Activation of the NF-kappaB transcription factor in a Tlymphocytic cell line by hypochlorous acid. Biochem J 321: 777-785. doi: 10.1042/bj3210777

- Schuller-Levis, G., Quinn, M.R., Wright, C., Park, E. (1994). Taurine Protects against Oxidant-Induced Lung Injury: Possible Mechanism(s) of Action. In: Huxtable R.J., Michalk D. (eds) Taurine in Health and Disease. Advances in Experimental Medicine and Biology, vol 359. Springer, Boston, MA. https://doi.org/ 10.1007/978-1-4899-1471-2 4

- Schumacher, B. (2009). Transcription-blocking dna damage in aging: a mechanism for hormesis. BioEssays News Rev. Mol. Cell. Dev. Biol. 31:13471356. doi: 10.1002/bies.200900107

- Siggaard-Andersen, O., Norgaard-Pedersen, B., \& Rem, J. (1972). Hemoglobin pigments. Spectrophotometric determination of oxy-, carboxy-, met-, and sulfhemoglobin in capillary blood. Clinica chimica acta; international journal of clinical chemistry, 42(1), 85-100. https://doi.org/ 10.1016/0009-8981(72)90380-4

- Silwood, C.J.L., Lynch, E.J., Seddon, S., Sheerin, A., Claxson, A.W.D., Grootveld, M.C. (1999). 1H NMR analysis of microbial-derived organic acids in primary root carious lesions and saliva. NMR Biomed 12:345-356. Doi: 10.1002/ (sici)1099-1492(199910)12:6<345::aidnbm580>3.0.co;2-c

- Simon, H.U. (2003). Neutrophil apoptosis pathways and their modifications in inflammation. Immunol. Rev. 193: 101-110. Doi: DOI: 10.1034/ j.1600-065x.2003.00038.x

-Tao, Y., Queen, K., Paden, C.R., Zhang, J., Li, Y., Uehara, A., et al. (2020). Severe acute respiratory syndrome coronavirus 2 isolate 2019-n CoV/USAIL1/2020, complete genome. NCBI GenBank. https://www.ncbi.nlm.nih.gov/nucleotide/ MN988713.1?

- US-ATSDR, (2004). Department of Health and Human Services. Toxicological Profile for Chlorine Dioxide and Chlorite. Sept. https:// www.atsdr.cdc.gov/toxprofiles/tp160.pdf

- US-EPA, (2000). U.S. Environmental Protection Agency. Toxicological review of chlorine dioxide and chlorite.Sept. https://cfpub.epa.gov/ncea/iris/iris_documents/ documents/toxreviews/0496tr.pdf
- Vandivier, R.W., Henson, P.M., \& Douglas, I.S. (2006). Burying the dead: the impact of failed apoptotic cell removal (efferocytosis) on chronic inflammatory lung disease. Chest, 129(6), 1673-1682. https://doi.org/ 10.1378/ chest.129.6.1673

- Van Slyke, D.D., and Hiller, A. (1946). Determination of carbon monoxide in blood and of total and active hemoglobin by carbon monoxide capacity; inactive hemoglobin and methemoglobin contents of normal human blood. The Journal of biological chemistry, 166(1), 121-148. PMID: 20273682 - Veerasarn, V. Boonnuch, W., Kakanaporn, C. (2006). A phase II study to evaluate WF10 in patients with late hemorrhagic radiation cystitis and proctitis. Gynecologic Oncology. Volume 100, Issue 1, Pages 179-184. https:// doi.org/10.1016/j.ygyno.2005.08.014

- Voll, R.E., Herrmann, M., Roth, E.A., Stach, C., Kalden, J.R., \& Girkontaite, I. (1997). Immunosuppressive effects of apoptotic cells. Nature, 390(6658), 350-351. https://doi.org/ $10.1038 / 37022$

-Weiss, S.J., Klein, R., Slivka, A., \& Wei, M. (1982). Chlorination of taurine by human neutrophils. Evidence for hypochlorous acid generation. The Journal of clinical investigation, 70(3), 598-607. https://doi.org/ 10.1172/ jci110652

-Winterbourn, C.C., van den Berg, J.J., Roitman, E., Kuypers, F.A., (1992). Chlorohydrin formation from unsaturated fatty acids reacted with hypochlorous acid. Arch.Biochem. Biophys. 296, 547-55. Doi: 10.1016/0003-9861(92)90609-z

-Winterbourn, C.C. (2008). Reconciling the chemistry and biology of reactive oxygen species. Nature chemical biology, 4(5), 278286. Doi: $\quad 10.1038 /$ nchembio.85 -Woods, C.G., Fu, J., Xue, P., Hou, Y., Pluta, L.J., Yang, L., Zhang, Q., Thomas, R.S., Andersen, M.E., \& Pi, J. (2009). Dose-dependent transitions in Nrf2-mediated adaptive response and related stress responses to hypochlorous acid in mouse macrophages. Toxicology and applied pharmacology, 238(1), 27-36. https:// doi.org/ 10.1016/j.taap.2009.04.007 - Yingsakmongkol, N., Maraprygsavan, P., Sukosit, J. (2011). Effect of WF10 (Immunokine) on Diabetic Foot Ulcer Therapy: A Double-blind, Randomized, Placebo-controlled Trial. Foot Ankle Surg. Vol 50, issue 6, 635-6 https:// doi.org/10.1053/j.jfas.2011.05.006 Zambrano-

- Estrada, X., Domínguez-Sánchez, C., BanuetMartínez, M., Guerrero de la Rosa, F., GarcíaGasca, T., Acevedo-Whitehouse, K. (en prensa). Evaluation of the antiviral effect of chlorine dioxide (ClO2) using a vertebrate model inoculated with avian coronavirus. https:// www.biorxiv.org/ content/10.1101/2020.10.13.336768v3.full.pdf 